\title{
Herman Eisen
}

$$
\text { (1918-2014) }
$$

\section{Immunologist and educator who discovered fundamentals of antibody binding.}

$\mathrm{H}$

erman Eisen made fundamental contributions to our understanding of how the body's immune system recognizes foreign structures. In an almost 70-year career, he showed how antibodies bind to antigens (surface molecules on viruses and bacteria) and measured how and why such binding strengthens, a concept that now dominates the field of vaccine design.

Eisen died in Cambridge, Massachusetts, on 2 November. He was born in 1918 into the Jewish community of Brooklyn, New York, one of four children, to parents who had emigrated from Eastern Europe. "I grew up with a sense that anti-Semitism in the world around us was pervasive, regarded as a fact of life, like birth and death," he later wrote. At age 16, he was interested in chemistry but enrolled as a premedical student at New York University (NYU), persuaded by his father that "large companies in the chemicals industry did not hire Jews. In medicine, however, a somewhat related field, one's destiny was in one's own hands."

While recuperating from tuberculosis during his university years, Eisen was deeply affected by two works: Sinclair Lewis's Arrowsmith (1925) and Charles Darwin's On the Origin of Species (1859). He was inspired by a seminar in which he learnt that moving a hydroxyl group on a benzene substituent from one carbon atom to another dramatically changed the compound's effect on a cat's blood pressure. It revealed to him the connection between molecular structure and biological function. As a resident in pathology at Columbia University in New York from 1944 to 1946 , Eisen was introduced to immunology in the laboratory of Michael Heidelberger, whose work had enabled the first demonstration that antibodies were proteins.

During his time as a medical resident at Bellevue Hospital Center, NYU's main teaching hospital, Eisen worked as a ship's surgeon on a voyage to South America. Between ministering to crewmen with minor injuries or syphilis, Eisen read Karl Landsteiner's superb 1936 summary of what was then known about immunology, The Specificity of Serological Reactions. The monograph argued for molecular complementarity as the basis for antigen recognition, a concept that inspired much of Herman's later work.

In 1948, Eisen received a senior National Institutes of Health fellowship grant of

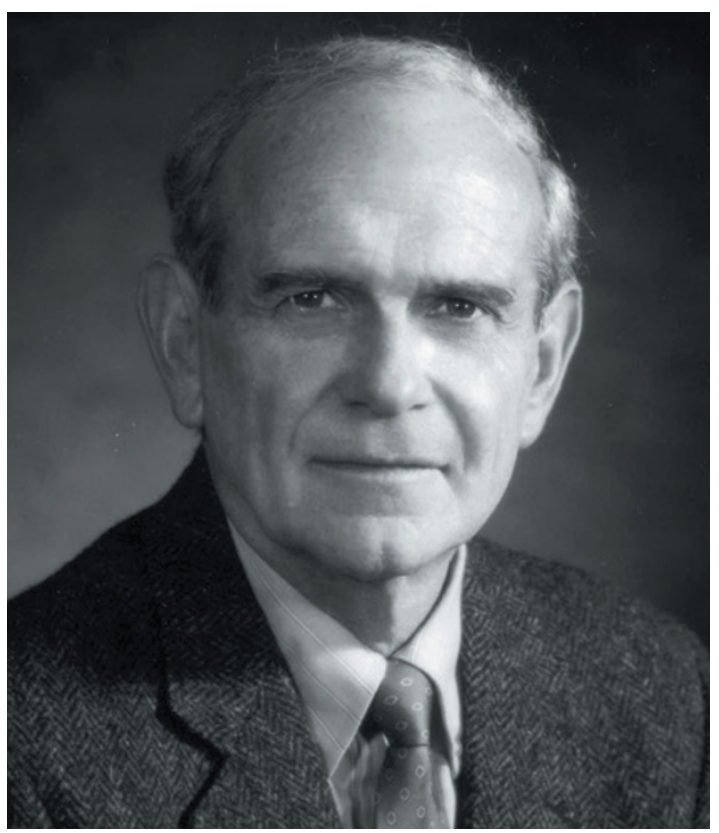

an ultrasensitive method to measure the strength of binding - the binding constant, or affinity - of antibodies for chemical entities such as dinitrophenol. He showed that binding becomes stronger the more time has elapsed since the first exposure to an antigen, because cells producing more tightly binding antibodies are preferentially stimulated as the amount of antigen diminishes. After repeated exposure to the same antigen ('booster' immunization) the tightly binding antibodies are synthesized without delay.

In 1973, he was recruited as a founding member to the newly established Center for Cancer Research (now the Koch Institute for Integrative Cancer Research) at the Massachusetts Institute of Technology in Cambridge. His research interests broadened to include recognition by receptors for antigens on blood cells known as T lymphocytes. He contributed to the discovery and characterization of the elusive T-cell receptor, and provided

US\$3,600 per year, freeing him to do fulltime research and to marry Natalie Aronson, a paediatrician, and start what became a family of five children. Working in the biochemistry department at NYU, Eisen, with Fred Karush, showed that antibodies typically possess two active sites that can bind antigens. This permits the formation of aggregates that are eliminated from the body. However, if such complexes lodge in joints or in the kidney, they can cause disease.

Next, Eisen moved to NYU's department of industrial medicine to explore allergic skin reactions to dinitrobenzenes. Working on his own skin and that of guinea pigs, he discovered that only those chemicals that are capable of forming covalent bonds to skin proteins cause the characteristic itchy rash. These studies led to his appointment in 1955 as professor of dermatology at Washington University in St. Louis, Missouri; he became chair of microbiology there in 1961.

Eisen was one of the handful of likeminded pioneers intent on understanding immune recognition who met periodically in a series of 'antibody workshops'. These advanced the problem of antibody diversity - how the body raises defences against different invaders - much as the RNA Tie Club, founded by James Watson and George Gamow, coalesced the pioneers of molecular biology.

At Washington University, Eisen developed experimental and conceptual tools to show the extraordinary sensitivity of 'killer' T lymphocytes, capable of responding to the presence of even a single antigen molecule as a means of eradicating a virus-infected cell.

At his house near Woods Hole, Massachusetts, Eisen indulged his passion for gardening, enjoying the biology and the aesthetics of what he nurtured. The author of an influential textbook, General Immunology (1990), Eisen was a sought-after mentor for students, postdoctoral fellows and sabbatical visitors.

With his unwavering curiosity and commitment to research, he was always available to discuss science, scheduling lunch dates to catch up with research areas in which he was interested but not necessarily active. Herman Eisen remained at the frontier of immunology: he was working on a manuscript and e-mailing coworkers the day that he collapsed en route to the gym, aged 96 .

Lisa Steiner is professor of biology at the Massachusetts Institute of Technology (MIT) in Cambridge, Massachusetts, USA. She worked under Herman Eisen as a postdoctoral researcher between 1962 and 1965 , and they were friends for more than 50 years. Hidde Ploegh is professor of biology at MIT, and worked with Eisen at the MIT Center for Cancer Research from 1992. emails: lsteiner@mit.edu; ploegh@wi.mit.edu 